\title{
Pharmacological Studies on Dregea Volubilis and Derris Trifoliate - The Medicinal Plants
}

\author{
Willy J. Shah ${ }^{1}$, Suhas P. Janwadkar ${ }^{2}$, Siddhesh B. Mangaonkar ${ }^{3}$, Siddhi Mhatre ${ }^{4}$ \\ ${ }^{1}$ Department of Chemistry, Annasaheb Vartak College of Arts, Commerce and Science, Vasai - 401202 \\ ${ }^{2,3,4}$ Department of Chemistry, Sonopant Dandekar, Palghar - 401404
}

\begin{abstract}
The present work aims to study the pharmacological studies such as physico-chemical and phytochemical screening on Dregea volubilis and Derris trifoliate. The samples were collected, washed, dried in hot air oven and were grinded to form fine powder. Both the powders were subjected to various physic-chemical tests such as ash value, water soluble ash, acid insoluble ash and loss on drying. Solvent optimization was carried out and it was found that water and organic solvent Methanol showed best extractive values. Further Methanolic extract was subjected to phytochemical screening which showed the presence of carbohydrates, alkaloid, flavonoids, tannins and phenols were present in both the plants.
\end{abstract}

Saponins were only present in Dregea volubilis plant powder.

KEYWORDS: Dregea volubilis, Derris trifoliate, physico-chemical, phytochemical, Methanol

\section{INTRODUCTION}

In modern medicine also, plants occupy a very significant place as raw material for some important drugs although synthetic drugs and antibiotics have brought about a revolution in controlling different diseases. [1] Plants used for traditional medicine contain a wide range of substances that can be used to treat chronic as well as infectious diseases.[2] The chemical compounds synthesized by plants as secondary metabolites commonly called as phytochemicals are of great interest in newer drug designing. Several of these plant derived compounds have different biological and other medicinal properties and are of increasing interest in therapeutic as well as other industrial applications.[3] The chemical constituents of the medicinal plants, particularly the secondary metabolites have pronounced pharmacological actions on animal systems and organs. Several bioactive compounds were isolated from the plant sources such as digoxin, digitoxin, morphine, reserpine, taxol, vinblastine, quercetin[2] Derris trifiliata (DT) of the family Fabaceae, alternatively Leguminosae is probably the only common climber that grows in mangroves, especially in Sundarban (mangrove forest) of India and Bangladesh. It is a perennial climber, or a much branched climbing evergreen shrub, reaching a length of 8 meters or less.[5] Wattakaka volubilis (L.f.) Stapf., (Syn. Dregea volubilis (L.f.) Benth. ex Hook.f., Marsdenia volubilis Cooke) belongs to the family Asclepiadaceae, is a tall woody climber, with densely lenticellate and pustular branches, leaves opposite, broadly ovate or suborbicular, cordate, acuminate, flowers bright yellowish-green, in lateral drooping, umbellate, cymes, follicle usually 2 , lanceolate covered with brown, mealy, tomentum, turgid, c. $2 \mathrm{~cm}$ long; seeds yellowish brown broadly ovate or broad elliptic, winged, comose.[6] Herbal medicines play an important role in the health-care system to alleviate and treat diseases. There is a great demand for medicinal plants in the herbal industry due to its health beneficiary properties with multi-dimensional chemical structures. Standardization of the medicinal plants is essential to confirm the authenticity and quality to avoid deliberate adulteration and substitution [7]

\section{MATERIALS AND METHODS}

\section{Physcio-chemical analysis}

The whole plant materials were collected from Nallasopara region, Palghar district, Maharashtra. The plant was washed and dried in hot air oven at $40^{\circ} \mathrm{C}$. The plant was crushed and sieved using 0.25 micro mesh sizes and stored in air tight container. The plant was subjected to physic-chemical analysis in accordance with the Practical Pharmacognosy book by Khandelwal K.R.

The following various physico-chemical parameters were analysed 


\section{International Journal of Current Science Research and Review}

ISSN: 2581-8341

Volume 04 Issue 04 April 2021

DOI: 10.47191/ijcsrr/V4-i4-11, Impact Factor: 5.825

IJCSRR@ 2021

www.ijcsrr.org

\section{Determination of total ash value}

Weigh about 2-4g of powdered plant into dish/crucible. Heat using burner until vapours almost cease to evolved, cool in a desiccator and weigh the ash and calculate the percentage of total ash with reference to the air dried samples of the plant.

\section{Determination of Water soluble Ash}

To the crucible containing the total ash, added $25 \mathrm{ml}$ of water and boiled for $5 \mathrm{~min}$. collect the insoluble matter in a sintered glass crucible or on an ash less filter paper. Washed with hot water and ignited in a crucible for 15 min. at a temperature not exceeding $45^{\circ} \mathrm{C}$. Calculate the content of water-soluble ash in $\mathrm{mg}$ per $\mathrm{g}$ of dried-material by subtracting the weight of this residue in mg from the weight of total ash.

\section{Determination of Acid insoluble Ash}

To the crucible containing the total ash, added $25 \mathrm{ml}$ of hydrochloric acid, covered with a watch glass and boiled gently for 5 min. rinsed the watch glass with $5 \mathrm{ml}$ of hot water and added this liquid to the crucible. Collect the insoluble matter on an ash less filter paper and washed with hot water until the filtrate is neutral. Transfer the filter-paper containing the insoluble to the original crucible, dried on a hot-plate and ignited. Allowed the residue to cool in a suitable desiccator for 30 min., and then weighed without delay. Calculated the content of acid-insoluble ash in mg per g air dried material.

\section{Determination of Loss on Drying}

The loss on drying test is used to measure the amount of water and volatile matters in samples, when the samples are dried under specific conditions. An empty crucible that has been dried under the same conditions was employed in the determination of loss on drying. The plant material was transferred to the empty crucible the quantity of the samples specified in the related monograph, covered it and accurately weighed the bottle and the contents. Distributed the samples as evenly as practicable by gentle sidewise shaking to a depth not exceeding 10mm. Placed the loaded bottle in the drying chamber (oven or desiccator) as directed in the monograph, removed the stopper and left it also in the chamber. The samples were dried to constant weight or for the specified time. After drying was completed, the crucible was allowed to cool at room temperature in a desiccator before weighing. Weigh the crucible and the contents.

\section{Optimisation of extractive values}

$1 \mathrm{~g}$ of plant powder was subjected to $10 \mathrm{ml}$ of water, Methanol, Acetonitrile, n-Hexane, Toluene and Chloroform, vortex and keep on shaker for $24 \mathrm{hrs}$, filter using whatmann filter paper no 41 . Transfer the filtrate to pre weighed crucible, evaporate the solvent and take the weight.

\section{Phytochemical Screening}

Qualitative analysis of phytochemical like carbohydrates, alkaloids, Tannins, Phenols, saponins and flavonoids were done with Methanol as an extracting solvent using practical Pharmacognosy by Khandelwal K.R.

\section{RESULTS}

The results of physic-chemicals values of whole plant powder of Dregea volubilis and Derris trifoliate were as follows:

Table 1: Physico-chemical parameters of leaves

\begin{tabular}{|c|l|c|c|}
\hline \multirow{2}{*}{ Sr. No } & Parameters & Values (\%) \\
\cline { 3 - 4 } & & Dregea volubilis & Derris trifoliate \\
\hline 1 & Total ash & 14.23 & 5.08 \\
\hline 2 & Acid insoluble ash & 1.55 & 1.03 \\
\hline 3 & Water soluble ash & 8.6 & 5.7 \\
\hline 4 & Loss on drying & 0.08 & 0.08 \\
\hline
\end{tabular}




\section{International Journal of Current Science Research and Review}

ISSN: 2581-8341

Volume 04 Issue 04 April 2021

DOI: 10.47191/ijesrr/V4-i4-11, Impact Factor: 5.825

IJCSRR@ 2021

www.ijcsrr.org

\section{Extractive values}

The results of extractive values with different solvents were recorded as follow.

Table 2: Extractive values

\begin{tabular}{|c|l|c|c|}
\hline \multirow{2}{*}{ Sr.no } & \multirow{2}{*}{ Solvents } & \multicolumn{2}{|c|}{ Extractive values (\%) } \\
\cline { 3 - 4 } & & Dregea volubilis & Derris trifoliate \\
\hline 1 & Water & 9.3 & 7.9 \\
\hline 2 & Methanol & 4.5 & 8.5 \\
\hline 3 & Acetonitrile & 2.1 & 1.8 \\
\hline 4 & Toluene & 2.6 & 1.6 \\
\hline 5 & Chloroform & 2.6 & 1.8 \\
\hline 6 & n-Hexane & 1.4 & 1 \\
\hline
\end{tabular}

Table 3: Phytochemical screening were as follow

\begin{tabular}{|c|l|c|c|}
\hline \multirow{2}{*}{ Sr.no } & Phytochemical & \multicolumn{2}{|c|}{ Observation } \\
\cline { 3 - 4 } & & Dregea volubilis & Derris trifoliate \\
\hline 1 & Carbohydrates & + & + \\
\hline 2 & Alkaloids & + & + \\
\hline 3 & Tannins & + & + \\
\hline 4 & Phenols & + & + \\
\hline 5 & Saponins & + & + \\
\hline 6 & Flavonoids & & + \\
\hline
\end{tabular}

(+ indicates presence and - indicates absence)

\section{DISCUSSION}

The plants are a very important source of phytochemicals. These phytochemicals changes with the change in environmental conditions. Hence standardization of plants is important factor in the study of plants. The present study aims to standardize such methods. Pharmacological studies were carried out on both the plants. Both the powder were subjected to physico-chemical parameters such total ash value, acid insoluble ash, water soluble ash and loss on drying and it was found to be $14.23 \%, 1.55 \%$, O.6\% and $0.08 \%$ respectively for Dregea volublis and $5.08 \%, 1.03 \%, 5.7 \%$ and $0.08 \%$ respectively for Derris trifoliate. Further both the powders were subjected for solvent optimization. Water, Methanol, Toluene, nHexane, Chloroform, Acetonitrile were used for extraction. Water showed the highest extractive value of $9.3 \%$ and $7.9 \%$ for Dregea volubilis and derris trifoliate respectively. Methanol also showed highest extractive value amongst the other organic solvent. Methanolic extract of both the powders were subjected to phytochemical screening which showed the presence of carbohydrates, alkaloid, phenol, tannins and flavonoids in both the plants. Saponins were present only in Dregea volubilis. Hence pharmacological studies were successfully carried on both the plants.

\section{ACHNOWLEDGEMENT}

VIVA College of ARTS, COMMERCE \& SCIENCE, Virar West for providing the necessary facility to accomplish the work

\section{REFERENCES}

1. Bharathamma G. And Sudarsanam G., Phytochemical Investigation Of Aqueous Fruit Extracts Of Dregea Volubilis (Linn.) Benth, Indian Journal of Plant Sciences, (2015) Vol.4 (1) 


\section{International Journal of Current Science Research and Review}

ISSN: 2581-8341

Volume 04 Issue 04 April 2021

DOI: 10.47191/ijcsrr/V4-i4-11, Impact Factor: 5.825

IJCSRR@ 2021

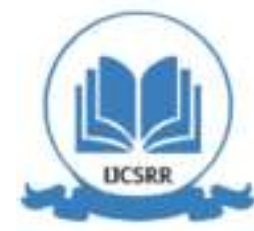

WWW.ijcsrr.org

2. R. Suganya, M. Thangaraj, Mangrove Plant Derris Trifoliata- Evaluation Of Antibacterial Property, Asian Journal Of Pharmaceutical And Clinical Research, (2014)Vol.7(1)

3. Aritra Simlai, Anjali Gangwar, Sarthaki Avinash Ghonge And Amit Roy, Antimicrobial And Antioxidative Activities In The Stem Extracts Of Derris Trifoliata, A Mangrove Shrub, Journal Of Pharmaceutical Research International, (2017)Vol.17(3)

4. Saifullah Al Mamoon And Md. Golam Azam, Preliminary Phytochemical Screening And Antidiarrhoeal Activity Of Derris Trifoliata Lour, International Journal Pharmaceutical Sciences And Research, (2012)Vol.3(1)

5. K. Babu1, N. Poornima, K.M. Umarajan, Anoop Austin, Studies On Histology And Phytochemical Evaluation Of Wattakaka Volubilis (L.F.) Stapf, International Journal Of Pharmaceutical Sciences Review And Research, (2016)Vol.41(1)

6. Bhaskar Das, Arnab De, Piu Das, Amalesh Nanda, Amalesh Samanta, Pharmacognostic Studies On Flowers Of Dregea Volubilis: Evaluation For Authentication And Standardization, Asian Journal Of Pharmaceutical And Clinical Research, (2019) Vol. 12(5)

7. P. Sudhakar, D. Kavitha And P. Ramachandra Reddy, A Preliminary Pharmacognostical Report On The Leaf Of Dregea Volubilis (L.F.) Benth. Ex Hook. F, Internatioanl Journal Of Pharmacognosy, (2018) Vol. 5(2): 97-102.

8. Thupurani Murali Krishna, Urmila Bonkuri, Racha Srikanth, Challa Surekha, Peddoju Pranay And Venkalapally Thirupathaiah., Phytochemical Analysis And Evaluation Of Antibacterial Activity Of Terminalia Chebula, Momordica Charantia, Dregea Volubilis Plant Extracts, International Journal Of Advance Research, (2018)Vol. 6(12), 1195-1201

9. Kanikaram.Naveen, Deepak Ragipati, A Madhavi, Preliminary Phytochemical Analysis Of Wattakaka Volubilis (L.F.) Stapf Leaf In Different Solvent Extracts, International Ayurvedic Medical Journal, (2017)Vol.5(10)

10. K. Ravi Shankar, Sanjoy Das And Pavani Bujala, Phytochemical Screening And In Vitro Antibacterial Activity Of Ethanol And Aqueous Extracts Of Dregea Volubilis Leaves, Biosciences, Biotechnology Research Asia, (2010) Vol. 7(2), 975-979

11. Venkatesan Natarajan And Anton Smith Arul Gnana Dhas, Phytochemical Composition And In Vitro Antimicrobial, Antioxidant Activities Of Ethanolic Extract

Of Dregea Volubilis (Linn.) Leaves, Advances In Biological Research (2013) 7 (3)8188,

12. S.Venkatesan, V. Balamurugan, A. Sundaresan, P. Susindran, K. Vasanthi, E. Subashini, M. Anithakumari Phytochemical Screening, Ft-Ir Analysis And

Antimicrobial Activity Of Wattakaka Volubilis, International Journal Of Biological Research, (2016) Vol.4 (2) 165-169

13. Moulisha Biswas, Pallab Kanti Haldar, Ashoke Kumar Ghosh, Antioxidant And FreeRadical-Scavenging Effects Of Fruits Of Dregea Volubilis, Journal Of Natural Science, Biology And Medicine (2010)Vol. 1(1).

14. Purushoth Prabhu T, Selvakumari S, Thirumal P, Susmitha, Deepthi, Preliminary Phytochemical And Standardization Of The Plant Dregea Volubilis., Benth, International Journal Of Bioassays (2012)Vol.1,(8).

15. Aritra Simlai, Anjali Gangwar, Sarthaki Avinash Ghonge And Amit Roy, Antimicrobial And Antioxidative Activities In The Stem Extracts Of Derris

Trifoliata, A Mangrove Shrub, Journal Of Pharmaceutical Research International, (2017)Vol.17(3): 1-10,

16. N. Sharief Md, A. Srinivasulu, P. Satya Veni, Uma Maheswara Rao V, Screening And Evaluation For Antibacterial And Antioxidant Potentials In Stem Extract Of Derris Trifoliata L, International Journal Of Pharmaceutical Research And BioScience, (2014)Vol.3(2): 424-435

17. Nymathullah. Sharief Md, A. Srinivasulu P. Satya Veni And Uma Maheswara Rao V, Identification Of Secondary Metabolite And Screening For Antibacterial And

Antioxidant Activity In Leaf Extracts Of Derris Trifoliata L., Journal Of Pharma Research, (2014)Vol. 3(4)

18. Muhammad Ali And Idris S Ibrahim, Phytochemical Screening And Proximate Analysis Of Garlic (Allium Sativum), An Archive Of Organic And Inorganic Chemical Sciences, 2019,4(1) 478-482

Cite this Article: Willy J. Shah, Suhas P. Janwadkar, Siddhesh B. Mangaonkar, Siddhi Mhatre (2021). Pharmacological Studies on Dregea Volubilis and Derris Trifoliate - The Medicinal Plants. International Journal of Current Science Research and Review, 4(4), 324-327 